\title{
COLLEGE STUDENTS' COLLABORATIVE USE OF INSPIRATIONTM TO GENERATE CONCEPT MAPS IN AN EDUCATIONAL TECHNOLOGY CLASS
}

\author{
NANCY J. GILBERT \\ Marywood University, Scranton, Pennsylvania \\ BARBARA A. GREENE \\ The University of Oklahoma
}

\section{ABSTRACT}

Presented is a qualitative study of five groups of college students using Inspiration ${ }^{\mathrm{TM}}$ to construct concept maps in an educational technology class. Analyses addressed how the maps changed during the semester, how the course concepts were applied in a final project, and whether or not students reported that the concept mapping activity facilitated their learning. Participants easily learned to use Inspiration ${ }^{\mathrm{TM}}$ for developing concept maps. Findings suggest that the concept maps did reflect student learning and that when done in collaboration seemed to facilitate learning. However, collaboration did not come easily or successfully to two of the five groups. The final projects of students who were in problematic groups were less sophisticated than those developed by students who did work collaboratively on their concept maps. An important implication is that students need to be provided with more assistance in successful collaboration to effectively use the concept mapping tool.

Researchers and practitioners agree that traditional approaches to instruction often lead to learning that is fact-based and not useful beyond classroom situations. This problem of inert knowledge has been addressed by some through the adoption of more authentic approaches to instruction that are based, in part, on an examination of apprenticeship models of developing expertise. One critical difference between traditional classrooms and apprenticeship environments is the 
nature of the learning tasks. Rather than memorizing facts or practicing skills for tests, learners in apprenticeship environments are working on real world problems that require the integration of multiple pieces of information. These real world problems are too complex to be addressed expediently by a single individual, but rather they require a collective effort from people with differing expertise. Thus, educational researchers have studied the collaborative nature of scientific communities as a potential alternative to traditional classroom teaching that focuses on individuals working alone [1].

\section{THEORETICAL RATIONALE: COLLABORATIVE LEARNING AND CONCEPT MAPS}

An emphasis on collaboration is based on the idea that people working together can build an aggregate body of knowledge far greater than people working as individuals [1]. The multiple perspectives they bring to a task will include a variety of experiences, expertise, and approaches to the solution of complex problems. Effective collaboration requires establishing a shared understanding of the problem and the solution. The process of establishing a shared understanding will typically stimulate a metacognitive process whereby the group members engage in questioning, clarifying, reflecting, and elaborating $[2,3]$.

In order to achieve a shared understanding during a collaborative process, a tool is needed for externalizing the group's current understanding of the material. Such a representational tool should encourage the group members to inspect, analyze, and elaborate on their current understanding [4]. Several examples of representational tools include spreadsheets, flowcharts, outlines, diagrams, cognitive maps, and semantic webs. These are different types of tools that can be used to make a group's knowledge overt in order to promote shared understanding. Concept mapping, which is the tool examined in this study, is a technique for organizing and integrating new information with information previously learned [5].

Concept maps are two-dimensional, dynamic diagrams that illustrate relations among ideas in a content area. They are spatially organized with keywords linked by labels identifying the type of relations among the concepts/ideas [5]. Concept mapping is a strategy that allows learners to map their understandings of diverse concepts in a particular content area. This technique has often been used to aid in learning fact-based information $[6,7]$ and has often involved teacher-generated maps [8]. However, concept mapping can also be used in more authentic and constructivist ways, in order to facilitate higher-order thinking when learners are encouraged to work collaboratively to generate successive maps over the course of their learning.

Concept mapping can be used as a technique to facilitate a collaborative process through cooperative group interaction as the group members reach consensus on the map organization. When heterogeneous groups are formed to capitalize on differences in background and experiences, the members should be able to benefit 
from the distributed intelligence. This should lead to a more robust graphical depiction, relative to the maps generated by individuals, of the relations among the theoretical constructs. The intention of this type of instructional strategy is to encourage the development of cognitive structures that are sufficiently complex in nature to allow for knowledge to develop from fact-based understandings to application level understandings. Given that learners in collaborative learning situations are expected to inspect, analyze, and elaborate on their current knowledge [4], their concepts maps should change incrementally as those processes continue to restructure their knowledge.

Inspiration $^{\mathrm{TM}}$ is a dynamic tool that enables the learners to work in groups to create a map of nodes and labeled links that depict the relations among key ideas in a content domain. Inspiration ${ }^{\mathrm{TM}}$ is a flexible tool that allows the map's organization to be easily modified by the group members to reflect their changing and developing understanding [9]. The software is intuitive and easy to use as nodes and links can be repositioned by clicking, dragging, and dropping. Inspiration ${ }^{\mathrm{TM}}$ contains a variety of graphic libraries that allow the user to personalize the pictorial representation of the nodes. Importantly, Inspiration ${ }^{\mathrm{TM}}$ allows students to easily make revisions so that they can record the changes in their developing knowledge. Additionally, the basic features of this program can be learned in 15 minutes or less based on experience by the first author. The only limitation noted was that the full map could not be viewed on a single screen, but had to be printed out and pieced together.

\section{PURPOSE AND RESEARCH QUESTIONS}

The purpose of the present study was to investigate how concepts maps, created by groups of college students taking an educational technology class, evolved over time and how the concept maps were reflected in a project that required the application of theoretical concepts to the solution of a real-world instructional problem.

Specifically, we addressed the following three questions.

1. How did the concepts maps change over the course of a semester?

2. How were the concepts applied in the final course project? Did the level of integration and elaboration in the individual's project seem consistent with the group's map?

3. Did the individual students report that the concept mapping activity facilitated their learning?

\section{METHOD}

\section{Participants and Design}

Fifteen pre-service teachers from a large university in the Southwest participated in the study (9 females; 6 males). There were 11 Caucasian, 1 African-American 
male, 1 Native American female, and 1 female from Spain with English as a second language. The students were volunteers from an Educational Technology course at a state university. The students were assigned to heterogeneous groups (five groups with three students per group) based on curriculum area and computer expertise. Each student was given a pseudonym to protect his/her identity during the reporting of data. Group 1 had Pam, Clare, and Walter; Group 2 had members Jen, Sam and Gail. Group 3 was composed of Ken, Carrie, and Vanita; Group 4 had Denise, Hannah and Matt; and Group 5 had Gary, Ben, and Tanisha.

\section{Context of the Course}

The study occurred within a 15 week, 3 credit hour undergraduate course required for preservice teachers. The primary goal of the course was to provide theoretical and practical information and experiences for integrating technology into $\mathrm{K}-12$ classrooms. The course was designed based on the principles of collaborative knowledge-building communities described by Scardamalia and Bereiter [1]. These principles incorporated the notions of cognitive apprenticeship and authentic learning. The apprenticeship process occurred as learners were guided by the instructor, third party tutorials, and a Web-based course tool that captured the results/products of class activities in the form of community artifacts. These artifacts were posted within the Web site and used in a collaborative fashion to raise the collective level of community understanding relative to the course goals. The class activities were authentic in that they were based on the types of real world instructional problems typically encountered in K-12 classrooms.

The first part of the course entailed reading eight current educational theory and research articles on topics such as knowledge-building communities, authentic instruction, metacognition, and use of technology to restructure $\mathrm{K}-12$ environments. A concept knowledge base was created within the course Web site from reaction papers written from the articles. The concept knowledge base included, for each concept a definition in the student's own words and excerpts from the articles showing how the concept was applied in instructional contexts. This information was used as the basis for the concept maps. Some of the concepts were: authentic activity; communities of learners (COL); constructivist; cooperative or collaborative learning; distributed intelligence; generative learning; higher-order thinking skills; instructional strategy; media attributes; metacognition; multiple perspectives; problem-based learning; scaffolds; self-regulated learning; situated learning and cognition.

\section{Data Sources}

There were six types of data that were collected and analyzed to address the research questions. The three main pieces used to address three questions were the concept maps, the final projects and the final course reflections. The other three were used to help interpret the main data and to provide a more complete picture of 
the groups and their effectiveness working collaboratively. All six are described below.

- Background surveys included questions on participants' educational background, familiarity with educational technology, and professional goals and experiences. These were used to create heterogeneous groups with group members who varied as a function of the grade level and content they planned to teach upon graduation and as a function of their level of computer expertise (so that, for example, all the students with high expertise would not be in one or two groups).

- The concept baseline was an open-ended questionnaire requiring definitions of the 25 concepts deemed central to the course content and domain. It was administered the first day of class for use as a baseline regarding student understandings.

- There were six concept maps generated over the semester by participants in five groups using the software Inspiration ${ }^{\mathrm{TM}}$. The concept maps were constructed to show how students understood the relations among the 25 concepts. Additionally, they were required to add five concepts per person to the map over the course of the semester. Students were instructed to work consistently throughout the semester on the map to promote their understanding and to reach consensus on the meaning of the ideas.

- The Final Project, also completed individually, was a written description of an instructional approach to a particular instructional problem. The document included a summary of the project, conceptual rationale, expected outcomes, evaluation, related theory-based concepts, and related articles.

- Group reports were submitted (by groups) during the semester. In the reports, the students reflected on the quality of the learning experience including group processing issues.

- Participants' Final Course Reflections were responses to a set of questions, submitted individually the last day of class, asking for specific feedback on aspects of the course. Among other questions, students were asked to rate the importance of each of nine course components on a scale from 1 to 10 with 1 being least helpful to 10 being most helpful. The purpose was to receive information on how the instructional strategies and conditions implemented in the course facilitated student learning.

\section{Analysis}

The design of the study was descriptive in nature, utilizing qualitative research methods derived from Miles and Huberman [10]. The data sources germane to each question were summarized and analyzed according to each research question for each group. For Question 1, concept maps were analyzed in terms of the number of concepts and the type and complexity of organization of the concepts into clusters. Clusters were defined as two or more concepts 
descriptively linked relative to overall map organization. We looked for breadth (i.e., the number of concepts) and depth (i.e., the extent to which the concepts were meaningfully grouped and linked). For Question 2, we examined the Final Projects submitted by each student in terms of whether the concepts included were coherently integrated in the Final Project (meaning that the concepts listed were applied in the solution to the instructional problem rather than merely listed). We also examined whether the use of concepts in the Final Project reflected the organization and complexity of the final Concept Map. For Question 3 , we simply looked at the rating each student gave the Concept Mapping activity and tallied those ratings up within the groups. Based on the initial analysis for each question, patterns were inferred from examining the data across groups. Both researchers summarized the data and then compared the results so that reliability in the analysis scheme could be achieved. The second level of analysis involved analysis of each research question through comparison of data across groups [11].

\section{RESULTS AND DISCUSSION}

\section{Question 1}

How did the concept maps change over the course of a semester?

There were three levels of clusters identified. See Figures 1, 2, and 3 for visual representations of the cluster levels. Primary clusters were organized close to the main idea and had at least three concepts descriptively linked either by line and/or label indicating a connection. Secondary clusters were embedded within the primary clusters or the main idea and had at least three concepts descriptively

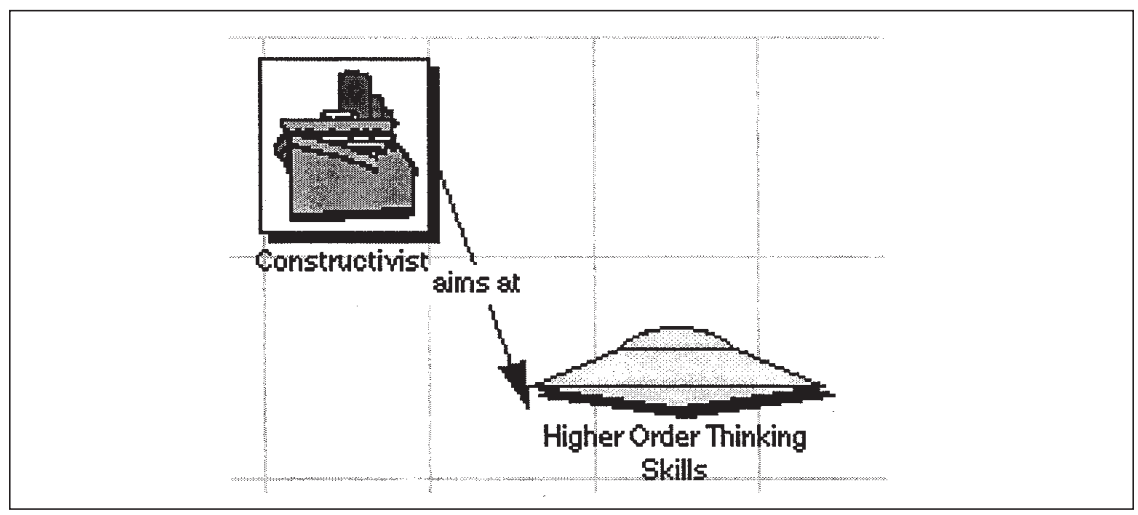

Figure 1. Primary Link Group 4-Main Idea is Constructivist 


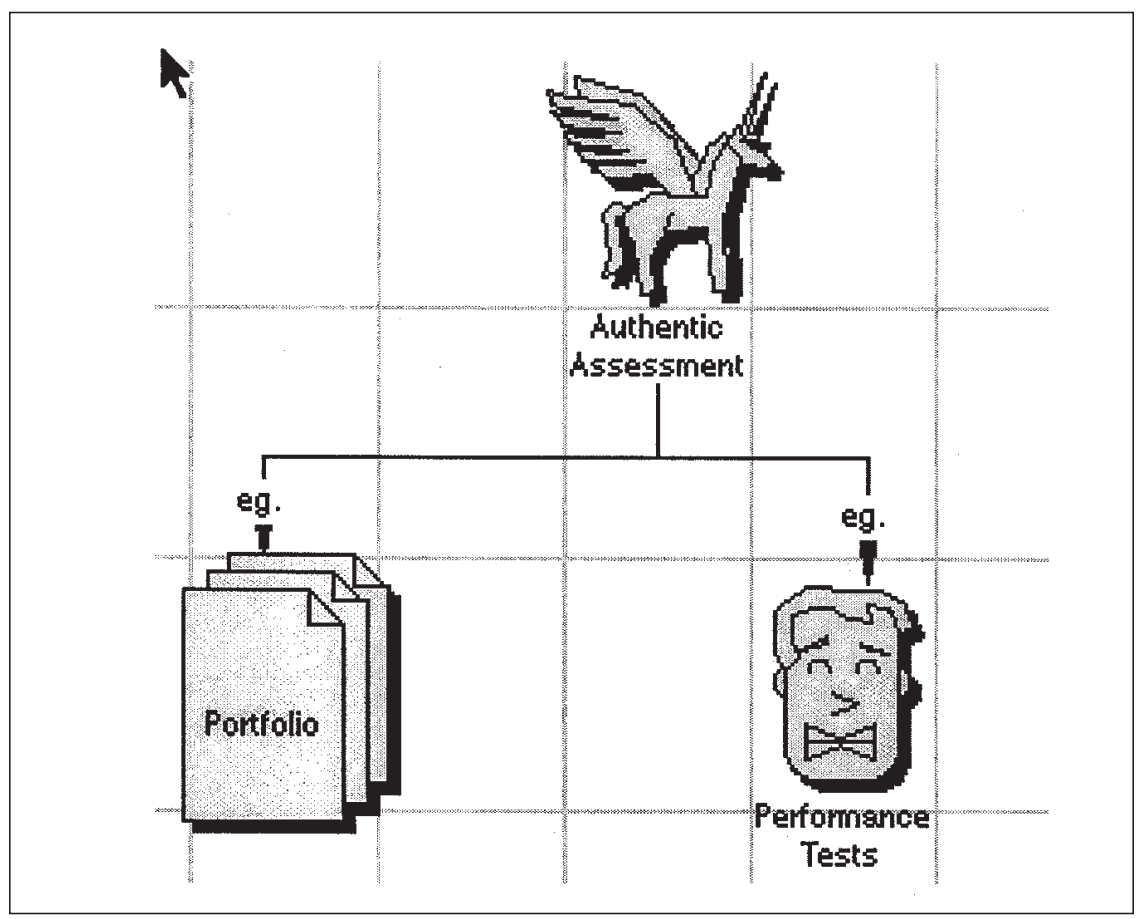

Figure 2. Secondary Link Group 4-Main Idea is Constructivist

linked either by line and/or label indicating a connection. Tertiary was embedded within a secondary cluster and also included at least three concepts descriptively linked either by line and/or label indicating a connection.

Each groups' maps were analyzed for change over the semester and then the maps were compared across groups. The concept maps were sampled 6 times over the 15 -week semester. The first map was a practice map to learn the Inspiration ${ }^{\mathrm{TM}}$ software and to understand how to reach consensus on understanding in groups, therefore the first map was not part of this analysis.

\section{Group 1}

The first map analyzed for Group 1 had 10 concepts with no links. Their next map contained 34 concepts using Constructivist as the main idea with the other concepts organized hierarchically. Three primary clusters (Educational Approaches, Planning, and Desired Educational Outcomes) were present and none of the links were labeled. Group 1 only modified their map three times during the semester rather than working consistently as instructed. Their final map, with the same three primary clusters, contained 44 concepts with the same hierarchical 


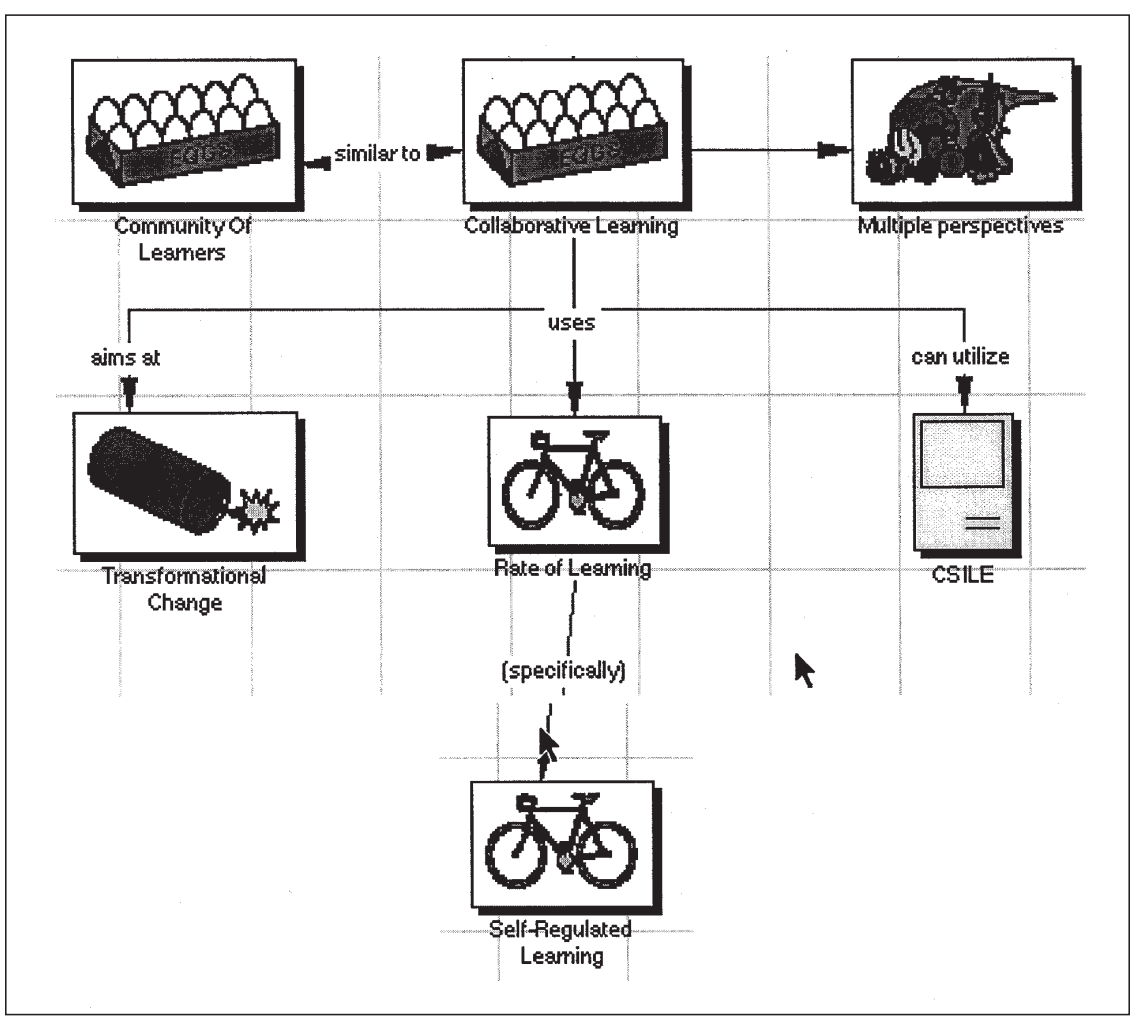

Figure 3. Tertiary Link Group 4-Main Idea is Constructivist

structure that emerged on the previous map. The major change on their final map was that most of the links were labeled. The labels included descriptors such as, authentic activity (concept), is a "type of" (label) problem solving (concept) that should "result in" (label), authentic assessment (concept). The organization of the two clusters on Educational Approaches and Planning seemed fairly elaborate based on the number of linked concepts, however, the cluster on Desired Educational Outcomes had no labels and lacked depth. In other words, the third cluster consisted of isolated concepts that were not labeled.

The process of working together collaboratively to reach consensus on understanding of the concepts did not seem to work out for this group as we noted in their group reports. The concept mapping activity did not come together in any coherent way perhaps because this group did not work on the map either collaboratively or incrementally. The final map appeared to be done by separate individuals rather than a well functioning cooperative group. 


\section{Group 2}

The first map analyzed from Group 2 had 8 concepts with all but one link labeled. Additionally, this was the only group that began with bi-directional links. Their main idea was Innovative Techniques for Teaching and Learning. The next map contained 11 concepts that demonstrated further elaboration. Similar growth was shown in their fourth map. On the subsequent map, there were 18 concepts and every link was labeled. The main idea, Innovative Techniques for Teaching and Learning was carried through until the final map with no secondary or tertiary clusters. However, the concepts within the single main idea were well integrated. For example, authentic activity (concept) as a strategy linked from the main idea using concept maps as an example (link). The final map had 42 concepts with Constructivist as the new main idea. There were 4 primary clusters from Constructivist, Methods, Authentic Activity, Collaborative Learning, and Instructional Technology. There were secondary clusters and one tertiary. The map demonstrated both depth and breadth of understanding.

\section{Group 3}

The first map analyzed for Group 3 had five concepts with one primary cluster, Constructivism. All the links were labeled. The next map had 11 linked concepts with the beginning of clusters, however the new links were not yet labeled. There were no changes in the next three maps. The final map contained 40 concepts keeping Constructivism as the main idea with two primary, three secondary, and three tertiary clusters. For example, Anchored Instruction (primary cluster) leads to Authentic Activity (secondary cluster) leads to Community of Learners (tertiary cluster). Community of Learners is further elaborated with three concepts, Collaborative Learning, Reciprocal Learning, and Cooperative Learning. There are no labels for the links, however directional arrows indicate the nature of the map's organizational structure. This final map clearly shows growth, however the substantive development occurred at the end rather than incrementally.

\section{Group 4}

Group 4 began their concept mapping activity with 11 concepts using Constructivist as the main idea. They also had a primary cluster, Visual Design, not linked to the main idea. Group 4 used a unique strategy in that they included concepts on the map that were not yet integrated. They listed these in the margins, ostensibly for future integration as their understanding grew. This strategy was used throughout the semester as their maps became progressively more complex. For example, they had 15 concepts in the next map and 20 in the subsequent map. In the next map, consisting of 24 concepts, Authentic Assessment was added as a primary cluster using Portfolios and Performance Tests as examples. The final map grew to 
41 concepts. There were four additional primary clusters and two secondary clusters. Although the map clearly shows breadth of understanding the organization did not demonstrate a high degree of complexity.

\section{Group 5}

The first map analyzed for Group 5 included 10 concepts with two primary and one secondary cluster. Their next map showed three additional concepts. No other growth was present. The next iteration had 20 concepts with an additional secondary cluster. The subsequent map had three primary and three secondary clusters. In the next version, they included the same number of primary and secondary clusters but in a different configuration. It appears as if the organization of their final map had been simplified. We found that one group member had acted alone to complete the final map. Additionally, Inspiration ${ }^{\mathrm{TM}}$ has a feature that allows the user to create 90 degree angles and straighten links that are curved or diagonal. This feature once activated automatically effects the entire map structure. It appears as if this occurred during the final map preparation. However, some of the labels were changed to indicate a deeper understanding of relations among the concepts. For example, Higher Order Thinking was shown as fostering Self-Regulation rather than Self-Regulation requiring Higher Order Thinking.

\section{Across Group Comparisons in Maps Changes over Course of Semester}

The data show evidence that while some groups worked steadily over the semester, other groups did the major portion of map construction on the final map. The disjointed organization of some of the maps indicate the concept mapping activity may not have been a collaborative effort. For example, the final maps created by Groups 1 and 5 suggested a non-collaborative approach. In the case of Group 1, the map was disjointed. In the case of Group 5, there was a discrepancy between the last 2 iterations of the map and we were told a single individual completed the final revision. Whereas in the other three cases, the maps seemed to be a result of collaborative effort.

Analysis of the concept maps across groups indicate that the level of complexity varied among the five groups over the course of the semester as did their application in the final course project. For example, unlike the other four groups, the map created by Group 1 was the least complex and maintained a purely hierarchical structure. Group 2 on the other hand, created a final map that was very sophisticated relative to the other groups. Evidence of collaborative effort was seen both in the organization of the map and in their final course reflections. 


\section{Question 2}

\section{How were the concepts applied in the final course project?}

The final projects developed individually by the students were anticipated to include application of a sampling of the theoretical concepts shown in the maps developed by the five groups. We examined the projects for evidence of meaningful, coherent application of the concepts. The results showed a variation in the level of complexity of concept integration in the final projects. For example, in Group 1 both Pam and Clare showed a surface-level application of the concepts. In Clare's case most of the concepts she listed as relevant seem quite independent of the described project. Pam had several obviously relevant concepts listed but also had some that were not clearly applied in her project. For example, she described her project in terms of the math skills, such as budgeting and conversion, that wold be learned while planning a trip using Internet resources. Her six concepts were: anchored instruction; computer supported intentional learning environments; constructivist; embedded education; scaffold; and world wide web. Her explanation of the project did not address how the concepts related except that she said the teacher might function as a scaffold in the learning environment.

This problem with Clare and Pam's application was consistent with the level of complexity (low-level hierarchical structure with few labeled links) shown in their maps. However, Walter, the third group member, showed sophisticated application of the theoretical concepts in his final project on how to use "The History Place" Web site to augment the traditional social studies curriculum. He included 12 concepts and noted how each fit with the goals of his project. For example, this student also had "scaffold" as a concept, but he explained that "Scaffolding would be necessary to make links to the people of the past and the contemporary people of today." Clearly, he had considered the actual application of the concepts. The group reports indicated that Walter was high in self-regulation and was able to learn independently even in the face of poor group functioning. Unfortunately, Pam and Clare were not as successful as independent learners and this may have contributed to the low level of coherency and complexity demonstrated in their final projects.

The three individuals in Group 2 all showed good integration of concepts in their Final Projects. Unlike the students in Group 1, these three had either 5 or 6 concepts that were clearly central to their project. Interestingly, all three had collaborative and/or cooperative learning as a key element in their projects, while no one in Group 1 had any group learning planned. The collaborative efforts of Group 2 seemed to be much more fruitful than those of Group 1 and this difference shows up in their final projects, which demonstrated a similar depth and breadth of understanding as shown in their final map.

Group 3 had one member, Vanita, who did not complete the project. The other two students, Ken and Carrie both had Final Projects that were very welldeveloped with the incorporation of concepts clearly explained. Both had fewer 
concepts than depicted on the final map, but Carrie had breadth similar to the final map, while Ken's project was more narrowly defined by concepts relating to authentic activity and collaboration. Both showed very good depth of understanding.

All of the Group 4 participants had Final Projects that were well-developed and to some extent more sophisticated than their final map. Although their final map showed more breadth than depth, the three Final Projects all showed more depth than breadth. We believe that this is a good outcome for an application project. All three projects were clearly based on constructivist principles involving collaboration, but for Denise and Hannah the peer interactions were more central than for Matt, who was more focused on the nature of the outcomes he was targeting (e.g., higher-order thinking skills and metacognition).

Ben was really the only Group 5 participant with a solid Final Project. All three had collaborative or cooperative learning as a concept, but only Ben explained the purpose of that concept in his social studies project. Tanisha had a lot of ideas and related concepts, but they did not come together to form a coherent lesson idea. Gary's project was even more baffling than Tanisha's. He provided very little description of his solution to the instructional problem and it seemed that five out of the eight concepts listed were unconnected to the project. Gary's general idea for the lesson was a simple, traditional Language Arts book report. Tanisha on the other hand, had complex lesson ideas geared toward encouraging students to be intrinsically motivated to learn about social problems. She just did not develop the ideas into a coherent plan.

In some cases there was a direct match between the concept map organization and in others the association was not as profound. It appears as if group functioning may have played a role in both the level of complexity relative to the concept map organization and how deeply the concepts were applied in the final projects.

\section{Question 3}

\section{Did the students report that the concept mapping activity facilitated their learning?}

In general, students who thought the concept mapping activity was useful were in groups that seem to have a high degree of collaboration. From both the Final Course Reflections and the Group Reports, we could tell that groups 1 and 5 did not function well. The data gathered from the Final Course Reflections from Group 1 indicated a varied opinion as to the utility of the activity. One individual rated concept mapping as a 1 out of 10 (with 10 being very helpful). The other ratings were 7 and 8 . Similarly for Group 3, the ratings on the final course reflections showed a disagreement in that one individual rated the concept mapping activity as a 4 with the entire group but a 10 with only one other member. 
This supports our inference noted earlier that the final map shown by Group 3 did not reflect a collaborative effort. For Group 4, the ratings of the degree of helpfulness from the final course reflections indicate an average rating of 8.7 out of 10 . For Group 2, the rating for the helpfulness of the concept mapping activity averaged a 7 out of 10 . Group 5 was another case in which one individual was dissatisfied with the concept mapping activity (4 out of 10) while the other group members found the activity very helpful.

\section{CONCLUSIONS}

We draw two major conclusions from our results. First, the evidence from the maps generated across the semester does tend to show changes in the maps that reflect developing knowledge. This means that our data do support the use of Inspiration ${ }^{\mathrm{TM}}$ to create maps to represent dynamic knowledge. This is consistent with the work of other researchers who have examined tools for organizing newly acquired or developing knowledge [4-9]. However, our second conclusion is that the changes reflected in the maps were not necessarily the result of the group collaboration as we had expected based on how the course was designed. For Groups 1 and 5, the map seemed to represent an individual's learning rather than the groups' learning. Contrary to what Scardamalia and Bereiter [1] have argued, we did not find that computer-based mapping tool facilitated group work in all cases. Instead, the inference we make from our findings is that it was easier for some students to learn how to use the concept mapping tool than it was for them to work collaboratively to apply the tool. We think our findings suggest that some college students need more guidance in group work in order for such work to actually facilitate their learning. Greene and Land came to a similar conclusion [3]. Alternatively, it might make sense to let some students work alone in developing their concept maps, though that is not the optimal use of the tool. There might be a benefit from the mapping exercise that is independent of the effects of collaboration. Future research should examine this possibility.

\section{Significance of Findings}

There is a growing body of knowledge about how active learning strategies, such as concept mapping, can be used to promote higher-order application of theoretical concepts rather than fact-based memorization. Additionally, the use of collaborative group work to support such higher-order application has been noted in the literature as one effective approach. This study represents a step toward providing empirically based information to assist in the development of these learning strategies and approaches. 


\section{REFERENCES}

1. M. Scardamalia and C. Bereiter, Computer Support for Knowledge-Building Communities, The Journal of the Learning Sciences, 3:3, pp. 265-283, 1984.

2. A. L. Brown and J. Campione, Communities of Learning and Thinking, or a Context by Any Other Name, in Developmental Perspectives on Teaching and Learning Thinking Skills. Contributions to Human Development, (Vol. 21), D. Kuhn (ed.), pp. 108-126, 1990.

3. B. A. Greene and S. M. Land, A Qualitative Analysis of Scaffolding Use in a Resource-Based Learning Environment Involving the World Wide Web, Journal of Educational Computing Research, 23:2, pp. 151-180, 2000.

4. K. Reusser, Tutoring Systems and Pedagogical Theory: Representational Tools for Understanding, Planning, and Reflection in Problem Solving, in Computers as Cognitive Tools, S. P. Lajoie and S. J. Derry (eds.), Erlbaum, Hillsdale, New Jersey, pp. 143-177, 1993.

5. D. Jonassen, M. Yacci, and K. Beissner, Structural Knowledge Techniques for Representing, Conveying, and Acquiring Structural Knowledge, Lawrence Erlbaum Associates, Hillsdale, New Jersey, 1993.

6. A. M. O'Donnell, Learning from Knowledge Maps: The Effects of Map Orientation, Contemporary Educational Psychology, 19, pp. 11-44, 1994.

7. K. Beissner, D. Jonassen, and B. Grabowski, Using and Selecting Graphic Techniques to Acquire Structural Knowledge, Performance Improvement Quarterly, 7:4, pp. 20-38, 1994.

8. P. D. Mitchell and S. G. Taylor, Concept Mapping as an Aid to Computer-Mediated Conversation: An Application of Conversation Theory, paper presented to the Association of Educational Communications and Technology, Orlando, Florida, 1991.

9. L. Anderson-Inman and L. Zeitz, Computer-Based Concept Mapping: Active Studying for Active Learners, The Computing Teacher, pp. 6-10, 1993.

10. M. B. Miles and A. M. Huberman, An Expanded Sourcebook: Qualitative Data Analysis (2nd Edition), Sage Publications, Thousand Oaks, California, 1994.

11. R. E. Stake, The Art of Case Study Research, Sage Publications, Thousand Oaks, California, 1995.

Direct reprint requests to:

Dr. Nancy Gilbert

Marywood University

Graduate Education Department

Director of Instructional Technology Program

2300 Adams Avenue

Scranton, PA 18509 